\title{
Risk factors for bronchial hyperresponsiveness in late childhood and early adolescence
}

\author{
P. Ernst, H. Ghezzo, M.R. Becklake
}

Risk factors for bronchial hyperresponsiveness in late childhood and early adolescence. P. Ernst, H. Ghezzo, M.R. Becklake. C) ERS Journals Ltd 2002.

ABSTRACT: The prevalence of asthma and bronchial hyperresponsiveness (BHR) tends to decrease in male children but increase in female children in the transition from childhood to adolescence. Hormonal factors may be involved in the natural history of asthma during this period.

In a prospective study of Montreal school children, the authors examined the determinants of BHR according to the child's pubertal status; 156 male children and 168 female children without a prior diagnosis of asthma were followed for an average of 4.6 yrs.

Average age at follow-up was 13.4 yrs and $59 \%$ had reached puberty. The prevalence of BHR at follow-up was similar among pre- and postpubertal male children $(25.0 \%$ versus $29.2 \%$ ), while BHR was more common among post- compared with prepubertal female children $(33.1 \%$ versus $14.2 \%)$. There were no differences in the determinants (measured in childhood) of BHR at follow-up according to pubertal status. The major determinant of BHR was a positive skin test to dust-mite antigen. BHR was also linked to exposure to gas cooking and the presence of exercise-induced bronchospasm.

In conclusion, the results of this study do not support a change in asthma phenotype with the onset of puberty. Pre- and postpuberty, the major determinant of bronchial hyperresponsiveness was skin sensitivity to mite allergen.

Eur Respir J 2002; 20: 635-639.
The Respiratory Epidemiology Unit, Dept of Epidemiology and Biostatistics, McGill University, Montreal, Canada.

Correspondence: M.R. Becklake, Respiratory Epidemiology Unit, McGill University, 1110 Pine avenue West, Montréal, Québec, Canada, H3A 1A3. Fax: 5143988981

E-mail: margaret.becklake@mcgill.ca

Keywords: Allergy skin test, asthma, exercise-induced bronchospasm, gas cooking, methacholine challenge test, puberty

Received: February 52002

Accepted after revision: April 62002

This work was supported by the Respiratory Health Network of Centres of Excellence (P.T. Macklem) and the Montreal Chest Research Institute.
Wheezing disorders in children are heterogenous in origin with different risk factors playing a determining role according to the age at which symptoms become and remain evident $[1,2]$. Early wheezing appears primarily related to airway size and viral infections [3]. The principle determinant of wheezing present at $\geqslant 6$ yrs is personal atopy, as evidenced by the presence of allergic sensitisation to common inhaled environmental allergens or an elevated serum immunoglobulin (Ig)-E [3-5], as well as a family history of atopic disorders [6]. The influence of viral infections on the occurrence of wheezing also diminishes from childhood to adolescence [7]. Wheezing disorders and their physiological correlate, bronchial hyperresponsiveness (BHR), also tend to remit [8, 9], especially among male children in whom wheezing in childhood is more common than in female children [10]. In contrast, late onset wheeze is more common among female children $[6,11]$. Differences in the natural history of wheezing disorders between male children and female children may be related to hormonal factors acting around the time of puberty $[12,13]$.

The authors therefore examined whether the determinants (measured in childhood) of BHR to methacholine (measured at follow-up) differed according to whether children had achieved puberty or not in a community based sample of Montreal schoolchildren followed over a 4-yr period.

\section{Subjects and methods}

The subjects examined and the methods used in the original cross-sectional survey have been described previously [14]. Briefly, a random sample of schools in central Montreal was selected stratified by socioeconomic status. Children in grades one (aged 5-7 yrs), three (aged 8 and 9 yrs) and five (aged 10-13 yrs) were selected for study. The parents were asked to complete a respiratory symptom questionnaire and the children completed a six-minute freerunning test in the school gymnasium for the determination of exercise-induced bronchospasm $(\geqslant 10 \%$ fall in forced expiratory volume in one second (FEV1) postexercise). A total of 989 children out of 1,274 eligible children successfully completed these tests between 1990-1992. Socioeconomic status was derived from parental occupation as described previously [14]. In addition home visits were made to a subset of 309 children where allergen skin-prick tests were carried out (details described elsewhere) [15]. In brief, solutions for testing included histamine $\left(1 \mathrm{mg} \cdot \mathrm{mL}^{-1}\right)$, normal saline, Dermatophagoides pteronyssinus, D. farinae, mixed grass pollens, tree pollens, ragweed, mixed moulds, Aspergillus spp., cat epithelium and cockroach. The mixed moulds comprised Alternaria tenuis, Aspergillus fumigatus, $A$. niger, A. oryzae, A. terreus, Hormodendrum hordei, 
$P$. chrysoganum, $P$. digitatum, $P$. expansum and $P$. notatum. These solutions were obtained from Omega (Montreal, Canada). A weal $\geqslant 3 \mathrm{~mm}$ in either direction was taken as a positive response if the normal saline control showed no reaction $(<1 \mathrm{~mm})$; otherwise, the size of the saline reaction was subtracted from the reaction of each allergen. If there was no positive response to histamine, skin testing was regarded as invalid.

For the second survey carried out from 1994-1996, 795 of the 989 children were traced to approximately 200 different schools in the Quebec school system. A total 448 of these children were tested at various sites. The study subjects were asked directly and confidentially about their smoking habits and underwent a methacholine test according to the method described by YAN et al. [16]. BHR was defined as a drop of $\geqslant 15 \%$ in FEV1 at a cumulative dose of methacholine of $\leqslant 12 \mu \mathrm{mol}$.

Table 1 shows the variables obtained at the first survey which were examined as potential determinants of BHR measured by the methacholine test carried out at the second survey. The relationship of these determinants to BHR was examined according to whether or not the children had achieved puberty at the second survey. Puberty was considered as attained in female children if they had started their menses (positive answer to the question to parents: "has she started her menstruations?") and in male children if their voice had changed (positive answer to the question to parents: "has his voice changed?").

The main study outcome was the presence of BHR. The prevalence per cent of subjects with the potential determinants of BHR was compared between subjects with and without BHR at the second survey using the Chi-squared test. Multiple logistic regression was used to examine the independent contribution of each of these variables. Variables were kept in the logistic model if the $\mathrm{p}$-value for their independent effect was $\leqslant 0.10$.

\section{Results}

Of the 989 children examined at the first survey, 448 children were traced and participated in at least some of the testing an average of 4-yrs later, (mean \pm SD: $4.58 \pm 0.72$ yrs) while 388 completed the methacholine bronchoprovocation test. For the purposes of the present study, 58 children for whom a doctor diagnosis of asthma was reported at the first survey, and six others for whom this question was not answered, were eliminated from further consideration, leaving 324 children in the present analysis. Subjects examined and not examined at the second survey did not differ significantly as to age, sex distribution, report of an asthma diagnosis, a history of parental asthma and/or smoking or the presence of exercise-induced bronchospasm, all measured at the first survey.

Table 2 shows some characteristics of 324 male and female children at the second survey according to their pubertal status. A greater proportion of female children (106 of $168,63 \%$ ) than male children ( 84 of $156,54 \%$ ) had reached puberty at the time of the second survey. Among prepubertal children, BHR was approximately twice as common among male children than among female children. After puberty the prevalence of BHR in male children was similar to the prevalence seen before puberty (29.2 versus 25.0), while among female children the prevalence had more than doubled and was more common in female children than male children $(33.1 \%$ versus $25.0 \%$ ). When BHR was assessed according to clinical criteria (fall of $20 \%$ at a cumulative dose of $\leqslant 4 \mu \mathrm{mol}$ ), the findings were similar (results not shown).

Table 3 shows the various potential determinants of BHR examined in relation to whether or not subjects had achieved puberty. In prepubertal children with and without BHR, the only substantial differences were low socioeconomic status (SES), gas cooking, mite allergy and exercise-induced bronchospasm

Table 1.-Definition of variables derived from information gathered at the first survey

Variables Question answered at the first survey

Family and household factors

Mother has asthma

Father has asthma

Older sibs

Shares bedroom

Low SES

Smoker at home

Smoking during pregnancy

Environmental factors

Gas cooking

Electric heating

Damp Spots

Cat at home

Daycare

Mite allergy

Exercise test

Exercise-induced bronchospasm
Does the child's natural mother suffer from asthma?

Does the child's natural father suffer from asthma?

Does the child have older siblings?

How many other people sleep in the bedroom with the child?

Lowest quartile of distribution of family socioeconomic status

At least one person smoking in child's home

Did the child's natural mother smoke during this pregnancy?

Is natural gas usually used for cooking?

Is your home heated by electric radiators or baseboard units?

Have you ever had wet or damp spots on surfaces inside your present home?

Do you keep any of the following in the home: cats, dogs, rodents, birds?

Did the child ever attend day care?

Weal $\geqslant 3 \mathrm{~mm}$ with skin-prick test to either $D$. pteronyssinus or $D$. farinae

$10 \%$ reduction in FEV1 after a free run lasting for 6 min

SES: socioeconomic status; D. pteronyssinus: Dermatophagoides pteronyssinus; D. farinae: Dermatophagoides farinae; FEV1: forced expiratory volume in one second. 
Table 2. - Characteristics according to sex and pubertal status at follow-up of 324 children without a history of asthma at the first survey

\begin{tabular}{lcccc}
\hline Subject characteristics & \multicolumn{2}{c}{ Male children } & \multicolumn{2}{c}{ Female children } \\
\cline { 2 - 3 } & Prepuberty & Postpuberty & Prepuberty & Postpuberty \\
\hline Subjects n & 72 & 84 & 62 & 106 \\
Age yrs & $12.4 \pm 1.6$ & $14.4 \pm 1.5$ & $11.6 \pm 1.4$ & $14.5 \pm 1.2$ \\
Height cm & $153.1 \pm 12.1$ & $167.1 \pm 9.5$ & $147.3 \pm 9.4$ & $161.3 \pm 7.1$ \\
Tried smoking \% & 24.7 & 47.0 & 15.3 & 57.8 \\
BHR \%\# & 29.2 & 25.0 & 14.2 & 33.1 \\
\hline
\end{tabular}

Data are presented as mean \pm SD unless otherwise stated. ${ }^{\#}$ : Bronchial hyperresponsiveness (BHR) to methacholine defined as $\mathrm{a} \geqslant 15 \%$ drop in forced expiratory volume in one second after inhalation of $\leqslant 12 \mu \mathrm{g}$ of methacholine.

Table 3. - Prevalence per cent of potential determinants of bronchial hyperresponsiveness (BHR) to methacholine, according to pubertal status at second survey\#

\begin{tabular}{|c|c|c|c|c|}
\hline \multirow[t]{2}{*}{ Potential determinants } & \multicolumn{2}{|c|}{ Prepubertal } & \multicolumn{2}{|c|}{ Postpubertal } \\
\hline & $\mathrm{BHR}+$ & BHR- & $\mathrm{BHR}+$ & BHR- \\
\hline Subjects $n$ & 36 & 98 & 56 & 134 \\
\hline \multicolumn{5}{|l|}{ Family and household characteristics } \\
\hline Mother has asthma & 5.6 & 9.2 & 7.1 & 4.5 \\
\hline Father has asthma & 2.8 & 5.1 & 0.0 & 2.2 \\
\hline Older sibs & 63.9 & 50.0 & 48.2 & 50.0 \\
\hline Shares bedroom & 38.0 & 43.9 & 35.4 & 43.3 \\
\hline Low SES & 38.9 & 23.5 & 30.4 & 24.6 \\
\hline Child reported having tried smoking at 2 nd survey & 25.0 & 17.4 & 50.0 & 52.2 \\
\hline Smoking by mother during pregnancy & 30.6 & 33.7 & 33.9 & 23.1 \\
\hline Smokers in the home & 11.1 & 16.3 & 21.4 & 24.7 \\
\hline \multicolumn{5}{|l|}{ Environmental factors } \\
\hline Gas cooking & 14.3 & 6.1 & 12.7 & $3.7 *$ \\
\hline Electric heating & 61.1 & 58.2 & 51.8 & 58.9 \\
\hline Damp spots & 8.3 & 9.2 & 7.1 & 5.9 \\
\hline Cat at home & 19.5 & 21.4 & 30.4 & 21.6 \\
\hline Day care & 34.3 & 38.1 & 29.6 & 37.6 \\
\hline Mite allergy & 38.9 & $20.4 *$ & 50.0 & $26.8^{*}$ \\
\hline \multicolumn{5}{|l|}{ Exercise test } \\
\hline Exercise induced bronchospasm & 27.8 & 14.3 & 26.8 & 14.2 \\
\hline
\end{tabular}

SES: socioeconomic status. ${ }^{\#}$ : All the variables examined were defined from information obtained in the first survey except for smoking by the child. BHR+ refers to the presence of as $a \geqslant 15 \%$ drop in forced expiratory volume in one second after inhalation of a cumulative dose of $\leqslant 12 \mu \mathrm{g}$ of methacholine. BHR- refers to its absence. *: $\mathrm{p}<0.05$.

at the first survey, all more common in those with BHR at follow-up. However only the difference in mite allergy (pre- and postpuberty) achieved the conventional level of statistical significance. In postpubertal children, the same determinants (low SES, use of gas for cooking, mite allergy and exerciseinduced bronchospasm) were substantially more frequent among subjects with BHR at follow-up, as well as smoking by the mother during pregnancy. However, only the differences in the prevalence of gas cooking and mite allergy achieved conventional levels of statistical significance. Note also that there was an association (nonsignificant) between current BHR and current smoking in prepubertal children which was not evident in postpubertal children. Current smoking was defined as having smoked 1 cigarette per day for $\geqslant 1$ month.

Table 4 examines the independent contribution of these various factors to the occurrence of BHR in a multivariable model. The estimates of effect are quite similar for the contribution of mite allergy, gas cooking and prior exercise-induced bronchospasm to the occurrence of BHR whatever the pubertal status. There is a trend towards an increase in BHR with smoking by the mother during pregnancy but only among subjects who have achieved puberty.

\section{Discussion}

In this follow-up study of children without a prior diagnosis of asthma including, for many, the transition from childhood to adolescence, the present authors found that BHR became more common among female children but that there were no substantial differences in the determinants of BHR according to whether or not puberty had been achieved. In either case, dust-mite sensitivity as determined by positive allergy skin-prick tests, the use of gas for cooking in the home during childhood and 
Table 4. - Factors independently associated with bronchial hyperresponsiveness (BHR) to methacholine in a multivariate logistic regression analysis

\begin{tabular}{lccccccc}
\hline Factors & \multicolumn{3}{c}{ Prepubertal } & & \multicolumn{3}{c}{ Postpubertal } \\
\cline { 2 - 3 } & Odds Ratio & $95 \%$ CI & p-value & & Odds Ratio & $95 \%$ CI & p-value \\
\hline Mite allergy & 2.6 & $1.1-6.1$ & 0.03 & & 3.0 & $1.5-6.0$ & 0.001 \\
Gas cooking & 3.4 & $0.9-12.4$ & 0.07 & & 3.5 & $1.0-12.3$ & 0.05 \\
Exercise-induced bronchospasm & 2.2 & $0.8-5.8$ & 0.11 & & 2.5 & $1.1-5.5$ & 0.03 \\
Mother smoked during pregnancy & 1.0 & $0.4-2.3$ & 0.93 & & 1.9 & $0.9-3.9$ & 0.09 \\
\hline
\end{tabular}

Variable definitions are provided in table 1. All factors listed in table 3 were included in this analysis. CI: confidence interval. Prepubertal, n=134; Postpubertal, n=190.

the presence, several years earlier, of exercise-induced bronchospasm, were the principal determinants of BHR to methacholine at follow-up.

The study hypothesis was that differences in the sex distribution of asthma between childhood and adolescence were related to hormonal changes in both male children and female children which might make them susceptible to different environmental determinants of asthma. The present authors expected that such differences would be easier to demonstrate in those children without a previous diagnosis of asthma, in whom genetic influences might be less strong [17]. While the influence of a family history of asthma was less evident in the present study population, as compared to other longitudinal studies of risk factors for asthma $[3,6,11]$, the determinants of BHR, or its symptoms, were quite similar to those found by others. For instance, LomBARDI et al. [17] reported on children from the Tuscon cohort who did not have asthma or recurrent wheezing by the age of $6 \mathrm{yrs}$. Over an average of 4.4 yrs of follow-up, the occurrence of asthma or recurrent wheeze was predicted in univariate analysis by airway hyperresponsiveness to cold air challenge, male sex, positive allergy skin tests and the report of wheeze also at age 6 yrs. In a multivariate model, only wheeze at age 6 yrs and atopy remained significant. The present authors could not carry out a similar analysis because the complaint of wheeze is quite uncommon in the Quebec French-speaking population [18]. WITHERs et al. [11], in a longitudinal cohort study, selected children, ages 6-8 yrs in 1987 who did not report wheeze, and reexamined them in 1995 for the occurrence of lateonset wheeze [11]. Late-onset wheeze was more likely to occur in female children and in those children with a personal or family history of atopy.

The principal outcome measure in the present study was BHR to methacholine. While this measure is not synonymous with asthma, it is a major feature of the condition and allows an important aspect of asthma to be examined without requiring a diagnosis and without being hampered by the differences in language alluded to above. Other studies have also looked at the determinants of BHR in the transition between childhood and adolescence. Burrows et al. [8] reporting on the findings from a New Zealand birth cohort, described a decrease in prevalence of BHR to methacholine from the age of $9-15 \mathrm{yrs}$, especially among male children and among those with lesser degrees of atopy as determined by allergy skin-prick testing. Similarly, Forastiere et al. [10] from Italy, found BHR to methacholine to decrease in prevalence from childhood to adolescence, though this was less likely to occur in atopic individuals and among female children. The present authors did not observe a substantial decrease in the prevalence of BHR with puberty. This may relate to the fact that, in contrast to the New Zealand and Italian studies, the present study only examined children without asthma at the outset. BHR to methacholine was, however, twice as common among female children who had attained puberty as compared to those that had not (33.1 versus $14.2 \%)$. The presence of exercise-induced bronchospasm at the first survey predicted the presence of BHR to methacholine an average of 4.58-yrs later. Since these are two measures of BHR, this observation provides evidence that BHR will persist from childhood to adolescence, at least in a proportion of individuals, as has been described by others [8, 10, 19].

The present study also found an increase in the prevalence of BHR with exposure to gas cooking in the home to be of similar magnitude whether or not puberty had been attained. Adverse effects on respiratory health of gas cooking or of nitrogen dioxide generated by this cooking method, have been reported frequently, although not consistently [19]. The effect has been more pronounced among subjects with atopy and among female children [20-22]. Due to limitations in sample size, a possible interaction between sex or atopy with gas cooking could not be examined. There was a trend towards an increase in the prevalence of BHR among postpubertal children in relation to smoking during pregnancy by the child's mother. This should not, however be attributed solely to smoking during pregnancy, since mothers who smoked during pregnancy were also more likely to smoke at home while the child was growing up. Although adjustment for current smoking by the mother was included at the initial survey, the possibility that mothers who smoked during pregnancy also smoked more heavily or more persistently after the child was born cannot be ruled out. Note that numerous previous studies have documented the adverse effect of second hand smoke on symptoms or measures of airway function in children [23].

To conclude, the results of this study do not support differences in asthma phenotype in relation to the onset of puberty. The major determinant of bronchial hyperresponsiveness both before and after the 
onset of puberty was the presence of a positive skinprick test to mite allergen.

\section{References}

1. Wahn U, von Mutius E. Childhood risk factors for atopy and the importance of early intervention. J Allergy Clin Immunol 2001; 107: 567-574.

2. von Mutius E. Paediatric origins of adult lung disease. Thorax 2001; 56: 153-157.

3. Martinez FD, Wright AL, Taussig LM, Holberg CJ, Halonen M, Morgan WJ. Asthma and wheezing in the first six years of life. The Group Health Medical Associates. N Engl J Med 1995; 332: 133-138.

4. Peat JK, Woolcock AJ. Sensitivity to common allergens: relation to respiratory symptoms and bronchial hyper-responsiveness in children from three different climatic areas of Australia. Clin Exp Allergy 1991; 21: 573-581.

5. Burrows B, Martinez FD, Halonen M, Barbee RA, Cline MG. Association of asthma with serum IgE levels and skin-test reactivity to allergens. $N$ Engl J Med 1989; 320: 271-277.

6. Sears MR, Holdaway MD, Flannery EM, Herbison GP, Silva PA. Parental and neonatal risk factors for atopy, airway hyper-responsiveness, and asthma. Arch Dis Child 1996; 75: 392-398.

7. Stein RT, Sherrill D, Morgan WJ, et al. Respiratory syncytial virus in early life and risk of wheeze and allergy by age 13 years. Lancet 1999; 354: 541-545.

8. Burrows B, Sears MR, Flannery EM, Herbison GP, Holdaway MD, Silva PA. Relation of the course of bronchial responsiveness from age 9 to age 15 to allergy. Am J Respir Crit Care Med 1995; 152: 13021308.

9. Peat JK, Salome CM, Sedgwick J, Kerrebijn J, Woolcock AJ. A prospective study of bronchial hyperresponsiveness and respiratory symptoms in a population of Australian school children. Clin Exp Allergy 1989; 19: 299-306.

10. Forastiere F, Corbo GM, Dell'Orco V, Pistelli R, Agabiti N, Kriebel D. A longitudinal evaluation of bronchial responsiveness to methacholine in children: Role of baseline lung function, gender, and change in atopic status. Am J Respir Crit Care Med 1996; 153: 1098.
11. Withers NJ, Low L, Holgate ST, Clough JB. The natural history of respiratory symptoms in a cohort of adolescents. Am J Respir Crit Care Med 1998; 158: 352-357.

12. Becklake MR, Kauffmann F. Gender differences in airway behaviour over the human life span. Thorax 1999; 54: 1119-1138.

13. Redline SI, Gold D. Challenges in interpreting gender differences in asthma. Am J Respir Crit Med 1994; 150: 1219-1221.

14. Ernst P, Demissie K, Joseph L, Locher U, Becklake MR. Socioeconomic status and indicators of asthma in children. Am J Respir Crit Care Med 1995; 152: 570-575.

15. Demissie K, Ernst P, Becklake MR. Socioeconomic status and children atopy. Can Resp J 1996; 3: 53-57.

16. Yan K, Salome C, Woolcock AJ. Rapid method for measurement of bronchial responsiveness. Thorax 1983; 38: 760-765.

17. Lombardi E, Morgan WJ, Wright AL, Stein RT, Holberg CJ, Martinez FD. Cold air challenge at age 6 and subsequent incidence of asthma. A longitudinal study. Am J Respir Crit Care Med 1997; 156: 1863 1869.

18. Osterman JW, Armstrong BG, Ledoux E, Sloan M, Ernst P. Comparison of French and English versions of the American Thoracic Society Respiratory Questionnaire in a bilingual working population. Int J Epidemiol 1991; 20: 138-143.

19. Samet JM, Utell MJ. The risk of nitrogen dioxide: what have we learned from epidemiological and clinical studies? Toxicol Ind Health 1990; 6: 247-262.

20. Jarvis D, Chinn S, Luczynska C, Burney P. Association of respiratory symptoms and lung function in young adults with use of domestic gas appliances. Lancet 1996; 347: 426-431.

21. Corbo GM, Forastiere F, Agabiti N, et al. Effect of gas cooking on lung function in adolescents: modifying role of sex and immunoglobulin E. Thorax 2001; 56: $536-540$.

22. Kerkhof M, de Monchy JG, Rijken B, Schouten JP. The effect of gas cooking on bronchial hyperresponsiveness and the role of immunoglobulin E. Eur Respir $J$ 1999; 14: 839-844.

23. Jaakkola MS. Environmental tobacco smoke and respiratory diseases. Eur Respir Mon 2000; 5: 322-383. 